\title{
EVIDENCIAÇÃO DOS IMPACTOS AMBIENTAIS RELACIONADOS AOS RESÍDUOS SÓLIDOS: UM ESTUDO COM EMPRESAS DO RAMO DE MEDICAMENTOS LISTADAS NA B3
}

Flávia Monaco Vieira ${ }^{1}$ Vanessa Martins Pires ${ }^{2}$

Resumo: Considerando que as informações relacionadas aos impactos ambientais na gestão dos resíduos sólidos são voluntárias, este trabalho busca analisar se as oito empresas do ramo de medicamentos listadas na B3 estão cumprindo o seu papel socioambiental junto aos stakeholders. A análise de conteúdo foi empregada com o objetivo de identificar e analisar as informações investigadas nas demonstrações contábeis e demais relatórios divulgados pelas companhias no ano 2018. Os resultados demonstram que a maioria das empresas não evidenciam os impactos ambientais decorrentes dos resíduos sólidos. Além disso, as informações constantes na maioria dos documentos são insuficientes, quando não inexistentes, para avaliação desses impactos.

Palavras-chave: Evidenciação Ambiental; Resíduos Sólidos; Empresas de Medicamentos.

Abstract: Considering that the information related to the environmental impacts in the management of solid waste is voluntary, this work seeks to analyze whether the eight pharmaceutical companies listed in B3 are fulfilling their socioenvironmental role with stakeholders. Content analysis was used in order to identify and analyze the information investigated in the financial statements and other reports released by the companies in the year 2018. The results show that most companies do not evidence the environmental impacts resulting from solid waste. In addition, the information contained in most documents is insufficient, if non-existent, to assess these impacts.

Keywords: Environmental Disclosure; Solid Waste; Pharmaceutical Companies.

1 Universidade La Salle. E-mail: Flavia.201910304@unilasalle.edu.br,

Link para o Lattes: http://lattes.cnpq.br/3124206982085534

2 Universidade Federal do Rio Grande (FURG). E-mail: vmpires@furg.br.

Link para o Lattes: http://lattes.cnpq.br/8689985427148351 


\section{Introdução}

Questões ambientais têm sido difundidas em nível global e ganharam ênfase nas agendas governamentais. Nesse sentido, ações estão sendo empreendidas pela sociedade, visando à conservação do meio ambiente e práticas mais sustentáveis.

No contexto brasileiro, políticas públicas foram introduzidas, a fim de promover o desenvolvimento sustentável, estando associadas ao bem-estar social, à preservação do meio ambiente e ao desenvolvimento econômico. Um exemplo deste esforço é a implantação da Política Nacional de Resíduos Sólidos (PNRS), instituída pela Lei 12.395 de 2010.

Segundo orientação da PNRS, deve-se observar a seguinte ordem de prioridade na gestão e gerenciamento de resíduos sólidos: "não geração, redução, reutilização, reciclagem, tratamento dos resíduos sólidos e disposição final ambientalmente adequada dos rejeitos" (Art. 9o, Lei 12.305 de 2010).

Sabe-se que as empresas de medicamentos movimentam bilhões de reais todos os anos (ANVISA, 2019), e devido aos avanços da indústria farmacêutica, novos medicamentos são lançados ao mercado, contribuindo para a geração de um volume maior de resíduos. Os resíduos originados pelas empresas que prestam serviços de saúde podem apresentar risco biológico, químico ou radiológico, que causam danos ao meio ambiente e à saúde humana, quando mal gerenciados. Nesse sentido, os resíduos das empresas que prestam serviços na área da saúde merecem atenção especial em todas as suas fases de manejo (segregação, acondicionamento, armazenamento, coleta, transporte, tratamento e disposição final).

As organizações em geral são pressionadas a desenvolverem suas atividades de forma sustentável, podendo sofrer pressões de áreas como: governo, sociedade, órgãos reguladores, imprensa, grupos ambientalistas, pesquisadores, acionistas e instituições financeiras. Segundo Do Patrocínio et al. (2018, p.20), "[...] para atender a essas pressões, as empresas podem divulgar em seus relatórios uma maior quantidade de informações de caráter ambiental, não se limitando apenas às informações financeiras".

Entre os princípios e instrumentos introduzidos pela PNRS constam a responsabilidade compartilhada e a gestão integrada dos resíduos sólidos, contemplando as ações que devem ser empregadas na busca de soluções para os resíduos gerados. Considerando que as informações sobre os impactos ambientais são voluntárias, é importante discutir se as empresas do ramo de medicamentos, que merecem atenção especial em todas as fases de manejo dos resíduos sólidos, estão cumprindo o seu papel socioambiental junto aos stakeholders.

Nesse sentido, esta pesquisa tem como objetivo analisar a evidenciação dos impactos ambientais relacionados aos resíduos sólidos, nas oito empresas do ramo de medicamentos, listadas na B3. Para atingir tal objetivo, investigou- 
se a divulgação do volume e a classificação dos resíduos sólidos produzidos, além de informações sobre a destinação dos resíduos.

A pesquisa se justifica pelo potencial de risco dos resíduos dos serviços de saúde para a saúde pública e para o meio ambiente, além de estar alinhada à preocupação global em torno do acúmulo e da destinação dos resíduos sólidos (OLIVEIRA, 2020). Contribui com as pesquisas sobre impactos ambientais e responsabilidade corporativa ao identificar o grau de preocupação das empresas do ramo de medicamentos estabelecidas no Brasil em evidenciar o seu desempenho em relação aos resíduos sólidos produzidos. Além de discutir a importância da divulgação de informações ambientais aos stakeholders, as quais são utilizadas como subsídio para tomada de decisão sobre investimentos, como fonte de informação na análise do valor de mercado das empresas, ou ainda, como subsídio na avaliação do desempenho socioambiental das companhias.

\section{Princípios de desenvolvimento sustentável}

Questões ambientais têm sido amplamente discutidas e estão cada vez mais em evidência, buscando aliar o consumo e o desenvolvimento a um ambiente sustentável (RICARDO et al., 2017; VOSS et al., 2013).

As relações entre os interesses econômicos empresariais e suas externalidades sociais e ambientais são constantemente questionadas, pela preocupação da sociedade moderna mundial com a sustentabilidade (GIACOMIN et al., 2018; DE OLIVEIRA; FERREIRA, 2018). Para Ricardo et al. (2017, p. 92) o "desenvolvimento econômico e meio ambiente saudável são elementos indissociáveis".

Foi a partir da década de 1960 que as discussões sobre questões ambientais se intensificaram na sociedade mundial, aumentando a conscientização e as preocupações em torno do meio ambiente. Desde então vários encontros no âmbito mundial foram realizados, a fim de debater o assunto (MONTEIRO; FERREIRA, 2007).

Um dos primeiros relatos de desenvolvimento sustentável surgiu durante a primeira Conferência da Organização das Nações Unidas - ONU sobre meio ambiente, em Estocolmo, em 1972. O termo utilizado na época era ecodesenvolvimento e as questões ambientais eram analisadas sob a ótica corretiva. As propostas apresentadas na Conferência tiveram como base os dados divulgados pelo relatório do Clube de Roma e basicamente privilegiaram a correção dos problemas apontados pelo mesmo (SOUSA, 2005).

Na década de 1980, o termo ecodesenvolvimento deu lugar à expressão desenvolvimento sustentável, o que até então versava basicamente sobre mudanças em relação ao modo de produção e consumo, pregado pelo sistema capitalista, foi ampliado para discussões relacionadas com a temática ambiental. Nesta época, as questões ambientais passaram a ser analisadas sob uma nova ótica, de corretiva para preventiva (SOUSA, 2005). 
Com a publicação do Relatório Nosso Futuro Comum, em 1987, também conhecido como Relatório de Brundtland, pela Comissão Mundial sobre Meio Ambiente e Desenvolvimento - CMMAD da ONU, o desenvolvimento sustentável foi definido como "[...] aquele que atende às necessidades do presente sem comprometer a possibilidade de as gerações futuras atenderem a suas próprias necessidades" (CMMAD, 1991, p.46).

O relatório contribuiu para discussões que buscassem promover 0 desenvolvimento econômico, proteção ambiental e equidade social. A ótica preventiva da política ambiental dos anos 80 cedia lugar a uma nova ótica, agora integradora, que passou a combinar os aspectos econômicos e sociais com os ambientais, em busca da preservação do meio ambiente e de formas mais racionais de utilização dos recursos naturais (SOUSA, 2005).

Em suma, o desenvolvimento sustentável é visto como "à convivência pacífica entre pessoas, em equilíbrio com o planeta" (PNUD, 2012, p.4) e tem como desafio proporcionar avanço social e econômico, sem afetar o meio ambiente (KRUGER et al., 2017).

A sustentabilidade pode ser definida como a capacidade de se sustentar, de se manter. Para Mikhailova (2004, p.25-26) "desenvolvimento sustentável é aquele que melhora a qualidade da vida do homem na Terra ao mesmo tempo em que respeita a capacidade de produção dos ecossistemas nos quais vivemos".

\section{Contextualização sobre Resíduos Sólidos}

A geração de resíduos constitui-se um desafio a ser enfrentado pela sociedade moderna, requerendo atenção dos governantes para criação de políticas públicas e legislações orientadas no eixo da sustentabilidade ambiental e preservação da saúde.

No Brasil, em 2010, foi implantada a Política Nacional de Resíduos Sólidos (PNRS), instituída pela Lei 12.395, que prevê: a prevenção e a redução na geração de resíduos, tendo como proposta a prática de hábitos de consumo sustentável e um conjunto de instrumentos para propiciar o aumento da reciclagem e da reutilização dos resíduos sólidos (aquilo que tem valor econômico e que pode ser reciclado ou reaproveitado) e a destinação ambientalmente adequada dos rejeitos (aquilo que não pode ser reciclado ou reutilizado) (BRASIL, 2019). Antes da PNRS, Balbino e Balbino (2012, p.88) destacam que: "[...] esses resíduos sólidos eram negligenciados pelo poder público, legisladores e administradores".

Resíduo sólido: Material, substância, objeto ou bem descartado resultante de atividades humanas em sociedade, a cuja destinação final se procede, se propõe proceder ou se está obrigado a proceder, nos estados sólido ou semissólido, bem como gases contidos em recipientes e líquidos cujas 
particularidades tornem inviável o seu lançamento na rede pública de esgotos ou em corpos d'água, ou exijam para isso soluções técnicas ou economicamente inviáveis em face da melhor tecnologia disponível (BRASIL, 2010).

A PNRS classificou os resíduos sólidos quanto à sua origem e periculosidade. Os resíduos farmacológicos são oriundos dos serviços de saúde e considerados perigosos, por apresentarem características como toxicidade, patogenicidade, carcionogenicidade, teratogenicidade e mutagenicidade (BRASIL, 2010).

Segundo o Manual de Gerenciamento de Serviços de Saúde, "[...] os resíduos de serviços de saúde são parte importante do total de resíduos sólidos urbanos, não necessariamente pela quantidade gerada (cerca de 1\% a 3\% do total), mas pelo potencial de risco que representam à saúde e ao meio ambiente" (BRASIL, 2006, p.29).

A geração de resíduos constitui-se um grande desafio e "[...] os Resíduos dos Serviços de Saúde (RSS) se inserem dentro desta problemática e vêm assumindo grande importância nos últimos anos" (BRASIL, 2006). Um marco do esforço do Estado na criação de normativas que visam o manuseio correto dos resíduos dos serviços de saúde foi a publicação da Resolução CONAMA no 005/93, que definiu a obrigatoriedade de os serviços de saúde elaborarem o Plano de Gerenciamento de seus resíduos.

No Brasil, o mercado de medicamentos movimenta bilhões de reais todos os anos, envolvendo tanto a produção, quanto à distribuição e o consumo desses medicamentos, provocando um acúmulo de resíduos sólidos (BALBINO; BALBINO, 2011).

Os RSS que não apresentam risco biológico, químico ou radiológico podem ser encaminhados para reciclagem, recuperação, reutilização, compostagem, aproveitamento energético ou logística reversa. Esses rejeitos podem, também, ser encaminhados para disposição final ambientalmente adequada. $\mathrm{O}$ gerenciamento dos demais grupos que apresentam risco à saúde devem observar a legislação da ANVISA, Resolução da Diretoria Colegiada no 222/2018, que trata especificamente sobre o manejo, armazenamento, coleta e transporte dos resíduos e de destino de acordo com o grupo de risco específico (ANVISA, 2018).

Os impactos ambientais, oriundos do descarte de medicamentos no meio ambiente são relevantes, pois acabam afetando diferentes ecossistemas. Um fato preocupante diz respeito aos medicamentos que podem causar dependências físicas ou psíquicas, assim como antibióticos, hormônios, anestésicos, anti-inflamatórios, entre outras substâncias lesivas (SOUZA; FALQUETO, 2012).

Em decorrência do avanço tecnológico da indústria farmacêutica, novos 
resíduos, além de conterem a presença de componentes complexos que devem ser considerados na avaliação dos riscos ambientais derivados dos resíduos farmacêuticos.

Salienta-se que os resíduos do serviço de saúde "[...] merecem atenção especial em todas as suas fases de manejo (segregação, acondicionamento, armazenamento, coleta, transporte, tratamento e disposição final) em decorrência dos imediatos e graves riscos que podem oferecer" (BRASIL, 2006, p.30).

\section{Evidenciação ambiental por parte das organizações privadas}

Preocupações sobre os impactos ambientais, atreladas ao aumento da conscientização da sociedade, aumentam a demanda por uma maior divulgação de informações sobre o tratamento dado aos recursos do meio ambiente (DO PATROCÍNIO et al., 2018).

Nesse sentido, a evidenciação de informações sobre os impactos ambientais gerados pelas empresas pode minimizar a assimetria informacional entre as empresas e os stakeholders. A evidenciação é o ato de comunicar aos usuários informações relevantes, auxiliando-os nas tomadas de decisões. $O$ objetivo da evidenciação de informações ambientais "[...] é divulgar, para os stakeholders, informações sobre o desempenho das entidades nas questões ambientais, bem como divulgar toda a informação que afete o meio ambiente e o patrimônio das entidades" (MONTEIRO; FERREIRA, 2007, p.87).

A evidenciação de informações de caráter ambiental amplia o grau de transparência das empresas acerca de suas atividades, além de ampliar a percepção de valor empresarial e afetar positivamente a sua reputação (POTRICH et al., 2017; DO PATROCíNIO et al., 2018). A evidenciação de informações ambientais também contribui no desenvolvimento do papel social das empresas e fomenta o desenvolvimento sustentável (RICARDO et al., 2017).

A evidenciação de informações ambientais está em consonância com os princípios de responsabilidade social corporativa, pois aborda "a ética na condução dos negócios, a transparência no relacionamento com os stakeholders e o compromisso da empresa com o desenvolvimento sustentável' (MONTEIRO; FERREIRA, 2007, p.83). Empresas cujas atividades afetam o meio ambiente e que não divulgam informações ambientais aparentam desconhecimento ou desinteresse sobre a sua responsabilidade socioambiental.

Atualmente não há uma legislação que obrigue as companhias a divulgarem informações de caráter ambiental, porém algumas empresas, cientes da importância de gerar informações ambientais relevantes aos seus stakeholders, estão cada vez mais dispostas a evidenciar essas informações, em maior quantidade e de melhor qualidade (DO PATROCÍNIO et al., 2018).

É importante comentar que alguns fatores podem prejudicar a organização na evidenciação de informações socioambientais, estes fatores são 
denominados: barreiras. "As empresas se deparam com fatores externos e internos à organização que assumem o aspecto de barreiras para a adoção da evidenciação" (DE OLIVEIRA; FERREIRA, 2017, p.62).

De Oliveira e Ferreira (2017) analisaram os motivos para não evidenciação de relatórios socioambientais. Os autores identificaram, por meio da revisão da literatura, onze fatores que foram divididos em dois grupos: barreira externa e interna.

No Quadro 1 são apresentadas, sinteticamente, as barreiras e os fatores relacionados à evidenciação de relatórios socioambientais.

Quadro 1: As barreiras e seus fatores para a evidenciação de relatórios socioambientais

Consumidores;

Legislação e regulamentação governamental;

Fornecedores;

Concorrência;

Tecnologia;

Sociedade e imagem corporativa.

\section{BARREIRAS INTERNAS}

Fatores organizacionais e valores;

Custos;

Recursos humanos;

Disponibilidade de recursos;

Processos de melhoria contínua

Fonte: Adaptado de De Oliveira e Ferreira (2017).

Vários estudos discutem a evidenciação de informações ambientais, considerando o nível de evidenciação (DO PATROCíNIO et al., 2018), as variáveis determinantes do nível de divulgação de informações voluntárias ambientais (POTRICH et al., 2017; GIACOMIN et al., 2018); e os motivos da não evidenciação de relatórios socioambientais (DE OLIVEIRA; FERREIRA, 2018).

A pesquisa de análise de conteúdo de Monteiro e Ferreira (2007) sobre a evidenciação da informação ambiental nos relatórios contábeis evidenciou que há um predomínio na divulgação de informações ambientais de natureza qualitativa, pois o principal meio usado para divulgar as informações ambientais é o relatório ambiental. Algumas empresas não apresentaram nenhuma informação ambiental, enquanto outras apresentaram informações inconsistentes e/ou incoerentes; e poucas empresas divulgaram informações financeiras relacionadas ao seu desempenho ambiental.

Voss et al. (2013) pesquisaram a evidenciação ambiental relacionada aos resíduos sólidos de 86 companhias abertas no Brasil no ano de 2010, e concluíram que alguns assuntos foram evidenciados de forma precária ou foram desconsiderados, são eles: redução da produção de resíduos sólidos comparados ao período anterior, preocupação com passivos ambientais e logística reversa.

Do Patrocínio et al. (2018) realizaram um estudo entre os anos de 2004 e 2014 para verificar o nível de divulgação de informações ambientais das companhias siderúrgicas listadas na B3 (Brasil, Bolsa, Balcão). Os pesquisadores concluíram que as empresas siderúrgicas evidenciam mais 
critérios positivos do que os critérios de caráter negativo, ou seja, as empresas procuram evidenciar informações que favorecem a sua atuação ambiental.

Ricardo et al. (2017) concluíram que a probabilidade de uma companhia publicar o relatório de sustentabilidade ou relato integrado é expandida quanto maior for o tamanho da empresa ou quando a mesma fizer parte da carteira do Índice de Sustentabilidade Empresarial (ISE). O ISE é uma ferramenta para análise comparativa da performance das empresas listadas na B3 sob o aspecto da sustentabilidade corporativa, baseada em eficiência econômica, equilíbrio ambiental, justiça social e governança corporativa (B3, 2019).

\section{Método de Pesquisa}

A natureza desta pesquisa é aplicada, com abordagem qualitativa e quantitativa. Quanto aos objetivos classifica-se como exploratória, realizada por meio do levantamento bibliográfico e pesquisa descritiva, através da análise documental e de conteúdo, utilizando diversos documentos como fonte de coleta dos dados (GERHARDT; SILVEIRA, 2009).

A amostra da pesquisa é formada por companhias abertas com ações negociadas na B3, pertencentes ao setor de Saúde, subsetor Comércio e Distribuição, do segmento de Medicamentos e Outros Produtos (Quadro 2). Portanto, a amostra pesquisada contempla a população de empresas de medicamentos com ações negociadas na B3.

O filtro utilizado na definição da amostra foi realizado no dia 20 de novembro de 2019, através da classificação das empresas listadas na B3, presente no website da B3 S.A. (B3, 2019). O segmento de Medicamentos e Outros Produtos foi escolhido pelo potencial de risco dos resíduos sólidos gerados ao meio ambiente e à saúde pública.

Quadro 2: Empresas de Capital Aberto do Segmento de Medicamentos listadas na B3.

\begin{tabular}{|c|l|}
\hline RAZÃO SOCIAL & \multicolumn{1}{c|}{ ATIVIDADE PRINCIPAL } \\
\hline Biomm S.A. & $\begin{array}{l}\text { Licenciamento de Tecnologia para Produção de Proteínas } \\
\text { Terapêuticas Recombinantes, especialmente insulina. }\end{array}$ \\
\hline $\begin{array}{c}\text { Biotoscana Investiments } \\
\text { S.A. }\end{array}$ & $\begin{array}{l}\text { Desenvolvimento, Produção e Comercialização de Produtos } \\
\text { Farmacêuticos. }\end{array}$ \\
\hline $\begin{array}{c}\text { Dimed S.A. Distrib. de } \\
\text { Medicamentos }\end{array}$ & $\begin{array}{l}\text { Comércio Atacadista e Varejista de Medicamentos, Produtos de } \\
\text { Perfumaria e Toucador. }\end{array}$ \\
\hline Hypera S.A. & Fabricação de Medicamentos Alopáticos para Uso Humano. \\
\hline Nortec Quimica S.A. & $\begin{array}{l}\text { Química Fina. Fabricantes de Insumos Farmacêuticos Ativos. } \\
\text { Matéria-prima para Indústria Farmacêutica. }\end{array}$ \\
\hline $\begin{array}{c}\text { Ouro Fino Saúde Animal } \\
\text { Participações S.A. }\end{array}$ & $\begin{array}{l}\text { Fabricação e Comercialização de Produtos destinados ao Setor de } \\
\text { Saúde Animal. }\end{array}$ \\
\hline Profarma Distr. Prod. & $\begin{array}{l}\text { Distribuição de Produtos Farmacêuticos, Higiene Pessoal e } \\
\text { Cormacêuticos S.A. }\end{array}$ \\
\hline Raia Drogasil S.A. & Comércio de Produtos Farmacêuticos, Perfumarias e Afins. \\
\hline \multicolumn{2}{|l}{ Fonte: Elaborado pelas Autoras (2020). }
\end{tabular}

Revbea, São Paulo, V.16, № 5: 392-409, 2021. 
No processo de coleta de dados os seguintes documentos foram utilizados: a) balanços patrimoniais, b) demonstrações do resultado do exercício, c) notas explicativas, d) relatório da administração, e) formulário de referência da CVM, e f) relatório de sustentabilidade. Os dados foram coletados no website da Comissão de Valores Mobiliários (CVM), referentes ao exercício de 2018, com exceção dos relatórios de sustentabilidade divulgados pelas companhias, os quais foram consultados diretamente nos websites das empresas, no espaço destinado ao Relacionamento com os Investidores (RI).

A análise de conteúdo foi empregada com o objetivo de identificar e analisar as informações investigadas nos documentos divulgados pelas companhias. Para a condução da análise de conteúdo os documentos foram salvos eletronicamente e organizados para codificação e análise. Realizou-se a análise sistemática dos relatórios com o propósito de identificar as categorias pré-estabelecidas e o controle da frequência da aparição dos elementos investigados nos documentos, para posterior interpretação dos achados.

As variáveis pesquisadas estão dispostas no Quadro 3 e foram definidas com base em palavras-chave discutidas na Política Nacional de Resíduos Sólidos (PNRS), instituída pela Lei 12.395 de 2010, que orienta as empresas a observarem a seguinte ordem de prioridade no gerenciamento dos resíduos sólidos: "não geração, redução, reutilização, tratamento dos resíduos sólidos e disposição final ambientalmente adequada dos rejeitos" (2010, art. 9º).

Quadro 3: Variáveis pesquisadas

\begin{tabular}{|ll|}
\hline Resíduos Sólidos & Política(s) Ambiental(is) \\
Logística Reversa & Coleta "de resíduos" \\
Reutilização/Reuso & Reciclagem \\
Destinação "de Resíduos" & Tratamento "de Resíduos" \\
\hline
\end{tabular}

Fonte: Elaborado pelas Autoras (2020).

Identificados os documentos que continham as variáveis investigadas, procedeu-se a análise de conteúdo dos documentos, por meio da leitura deles na íntegra. A análise dos documentos complementou a análise de frequência das variáveis pesquisadas e apresentadas no Quadro 3, além da identificação de informações divulgadas que permitam conhecer características da gestão ambiental adotada pelas empresas.

$\mathrm{Na}$ análise dos dados buscou-se identificar se as empresas do ramo de medicamentos com ações negociadas na B3 evidenciaram o volume e a classificação de resíduos sólidos produzidos; se houve a divulgação da destinação e do tratamento dos resíduos sólidos; e se foi informada a gestão adotada no gerenciamento dos resíduos (logística reversa; coleta; reutilização e reciclagem). 


\section{Análise e discussão dos resultados}

Nesta seção apresentam-se os resultados. Primeiramente são apresentadas as frequências das aparições das variáveis investigadas, considerando cada uma das oito empresas como unidade de análise. $\mathrm{Na}$ sequência, discutem-se os resultados obtidos, considerando informações quantitativas e qualitativas presentes nos documentos consultados.

\section{Análise dos resultados}

Inicialmente realizou-se a identificação da aparição das variáveis predeterminadas: resíduos sólidos, política(s) ambiental(is), logística reversa, coleta, reutilização/reuso, reciclagem, destinação e tratamento "de resíduos", nos documentos disponíveis aos investidores (Demonstrações Financeiras, Relatório de Administração, Termo de Referência e Relatório de Sustentabilidade). As informações foram detalhadas na Tabela 1.

Tabela 1: Frequência da aparição das variáveis investigadas nas oito empresas de saúde listadas na B3

\begin{tabular}{|c|c|c|c|c|c|c|c|c|}
\hline Empresas & 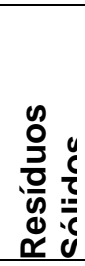 & 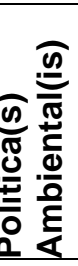 & 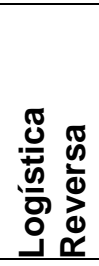 & 递 & 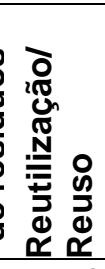 & 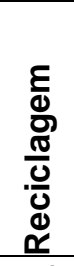 & 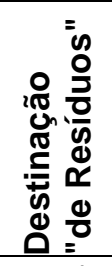 & 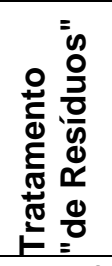 \\
\hline Biomm S.A. & 1 & 1 & 0 & 0 & 0 & 0 & 1 & 0 \\
\hline Biotoscana Investiments S.A. & 0 & 2 & 0 & 0 & 0 & 0 & 1 & 2 \\
\hline Dimed S.A. Distr. de Medicamentos & 0 & 1 & 0 & 0 & 0 & 0 & 1 & 0 \\
\hline Hypera S.A. & 5 & 2 & 1 & 1 & 2 & 1 & 5 & 3 \\
\hline Nortec Quimica S.A. & 0 & 0 & 0 & 0 & 0 & 0 & 1 & 1 \\
\hline Ouro Fino Saúde Animal Participações S.A. & 3 & 1 & 2 & 3 & 2 & 2 & 1 & 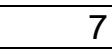 \\
\hline Profarma Dist. Prod. Farmacêuticos S.A. & 6 & 0 & 0 & 1 & 0 & 0 & 1 & 2 \\
\hline Raia Drogasil S.A & 8 & 1 & 1 & 3 & 1 & 1 & 11 & \\
\hline
\end{tabular}

Fonte: Elaborada pelas Autoras (2020).

Em relação aos documentos que subsidiaram a coleta dos dados presentes na Tabela 1, pode-se descrever que as Demonstrações Financeiras são documentos obrigatórios que apresentam a situação econômico-financeira da empresa, assim como o Relatório de Administração que evidencia o desempenho da administração na gestão e na alocação dos recursos a ela confiados. O Formulário de Referência, por sua vez, é um documento eletrônico, submetido à CVM, que reúne diversas informações, como atividades, fatores de risco, administradores, estrutura de capital, dados financeiros, valores mobiliários emitidos, entre outros. No item: fatores de risco, presente no Formulário de Referência, as empresas devem informar os fatores que podem influenciar a decisão de investimento por parte dos investidores. Por fim, o 
Relatório de Sustentabilidade é um documento no qual as empresas definem as ações referentes ao desenvolvimento sustentável, entretanto, sua publicação não é obrigatória.

A maioria das companhias analisadas apresenta a questão socioambiental como fator de risco no Termo de Referência, seja pelos riscos da gestão ambiental e legislação, já que possuem licenças ambientais e então qualquer irregularidade poderá ocasionar penalidades às empresas (Biomm; Dimed, Nortec Quimica, OuroFino), seja pelos riscos de alteração das propriedades físico-químicas do solo e da água, como, por exemplo, a geração de resíduo sólido com potencial contaminante (Biomm; Hypera, Nortec Quimica, OuroFino, Raia Drogasil) ou ainda, por acidentes ou falhas logísticas (OuroFino, Raia Drogasil).

Outros fatores de risco associados à questão socioambiental referem-se às ações ambientais que podem afetar adversamente a reputação do negócio, condição financeira ou ainda os resultados operacionais da companhia (Biotoscana). Além de riscos decorrentes de alterações nas condições econômicas globais, devido à volatilidade e incerteza que podem elevar os custos operacionais ou diminuir a disponibilidade de matéria prima (OuroFino), e preocupações sobre o consumo e utilização de recursos naturais: água, energia elétrica e combustíveis fósseis, cuja escassez pode impactar a operação, aumentando custos (Raia Drogasil).

Algumas empresas apresentaram as questões ambientais como efeitos relevantes da regulação estatal nas atividades, destacando como fatores, a política ambiental e os custos incorridos para o cumprimento da regulação ambiental e adesão a padrões internacionais de proteção ambiental (Dimed, Profarma), além de enaltecerem aspectos relacionados ao licenciamento ambiental, aos resíduos sólidos e à contaminação (Profarma).

A Biomm S.A. informa que faz automonitoramento de resíduos ambientais, porém não fornece detalhes sobre este monitoramento. Destaca que segue as principais normas ambientais vigentes, no entanto, não cita quais são estas normas.

Embora a Biotoscana Investments S/A apresente como fator de risco o envolvimento em ações ambientais, ela não apresenta detalhes dessas ações ambientais. Sobre a administração ambiental, a companhia informa que as instalações utilizam produtos e materiais que são considerados como lixo perigoso, para o qual o transporte, o armazenamento, o tratamento e o descarte final são regulados por várias autoridades governamentais, contudo não divulga a gestão ambiental, especialmente a gestão relacionada aos resíduos sólidos.

A Dimed S.A. informa que devolve aos fabricantes a maioria dos medicamentos sujeitos a descarte (com prazo de validade expirado ou com danos à embalagem), no entanto, não divulga dados sobre os demais resíduos gerados. Apesar de serem difundidas as campanhas socioambientais, não há evidenciação das questões ambientais relacionadas aos resíduos sólidos. 
Quanto à gestão ambiental, a Hypera S.A. informa que realiza o gerenciamento dos resíduos sólidos, visando reduzir os impactos ambientais de suas operações e contribuir com a preservação de recursos naturais, além de referenciar as campanhas realizadas. Embora a empresa relate suas campanhas e programas ambientais, ela não evidencia questões sobre o gerenciamento, volume e classificação dos resíduos sólidos.

A Nortec Quimica S.A. possui uma Estação de Tratamento de Efluentes (ETE) para tratar os rejeitos industriais gerados, na qual são produzidos - por sínteses químicas - mais de 50 Princípios Ativos Farmacêuticos. Contudo, a empresa não divulga nenhuma informação em relação aos resíduos sólidos gerados.

A Ourofino Saúde Animal Participações S.A. informa que está empenhada em desenvolver ações focadas na redução dos impactos ambientais, aderindo, entre outras práticas, o compromisso para logística reversa, que visa recolher $22 \%$ das embalagens de seus produtos no Estado de São Paulo. A companhia divulga o Relatório de Sustentabilidade, adotando a metodologia da Global Reporting Initiative (GRI).

Os resíduos são segregados de acordo com sua classe, acondicionados em local específico e destinados para tratamento, respeitando suas características. O descarte é realizado pela própria Companhia, enquanto o transporte e o tratamento são terceirizados. Para garantir a eliminação correta, a empresa Ourofino S.A. acompanha todas as etapas - agendamento, pesagem do caminhão, carregamento, emissão dos documentos e liberação do veículo do processo - até a emissão do Certificado de Destruição Final.

A companhia apresenta o tipo e método de disposição (em toneladas) dos resíduos e Transporte de resíduos perigosos, detalhados na Tabela 2.

Tabela 2: Evidenciação do tipo e método de disposição de resíduos e transporte de resíduos perigosos pela empresa Ourofino

\begin{tabular}{l|c|c} 
RESÍDUOS POR TIPO (em toneladas) & $\mathbf{2 0 1 7}$ & $\mathbf{2 0 1 8}$ \\
\hline Perigosos & 434,84 & 359,1 \\
\hline Não perigosos & 716,18 & 643,40 \\
\hline Total & $\mathbf{1 . 1 5 1 , 0 2}$ & $\mathbf{1 . 0 0 2 , 5 0}$ \\
\hline $\begin{array}{l}\text { MÉTODO DE DISPOSIÇÃO DOS RESÍDUOS (em } \\
\text { toneladas) }\end{array}$ & & \\
\hline Reciclagem & 241,46 & 229,72 \\
\hline Reutilização & 111,87 & 70,80 \\
\hline Aterro sanitário & 262,33 & 183,60 \\
\hline Recuperação de tambores & 100,52 & 159,30 \\
\hline Latões de aerossol & 23,33 & 45,70 \\
\hline Coprocessamento & 124,29 & 162,90 \\
\hline Incineração & 287,22 & 150,50 \\
\hline Total & $\mathbf{1 . 1 5 1 , 0 2}$ & $\mathbf{1 . 0 0 2 , 5 0}$ \\
\hline $\begin{array}{l}\text { TRANSPORTE DE RESÍDUOS PERIGOSOS (em } \\
\text { toneladas) }\end{array}$ & \\
\hline Resíduos perigosos transportados e tratados & 434,84 & 359,10 \\
\hline
\end{tabular}

Fonte: Adaptado de Ourofino (2019).

Revbea, São Paulo, V.16, № 5: 392-409, 2021. 
A Profarma Distrib. Prod. Farmacêuticos S.A. foi a única empresa que não destacou as questões socioambientais como fatores de risco, pois entende que suas atividades não estão sujeitas a riscos socioambientais relevantes, uma vez que suas atividades envolvem a comercialização de medicamentos.

Cabe destacar, que a Política Nacional de Resíduos Sólidos (PNRS) estabeleceu o Plano de Gerenciamento de Resíduos de Serviço de Saúde (PGRSS) aos seus geradores, mas não obrigou ao comércio varejista recolherem os medicamentos (sobras e/ou vencidos) e materiais (perfurantes, contaminantes) utilizados pelos clientes.

Por conseguinte, a Profarma S.A. comunica que as atividades de distribuição e comercialização de Medicamentos, Produtos Hospitalares, Especialidades e Vacinas, não geram impactos ambientais significativos e que não estão sujeitas a controle específico das autoridades ambientais, uma vez que o manuseio e a armazenagem dos produtos não afetam, de forma diretamente nociva, o meio ambiente.

A companhia informa que não gera resíduos sólidos que necessitem de gerenciamento especial ou efluente líquido perigoso e que não realiza quaisquer atividades de disposição final (descarte) dos referidos produtos incluindo os vencidos, com problemas de fabricação, entre outros. Em geral, todos os produtos sujeitos a descarte são devolvidos aos seus respectivos fabricantes ou encaminhados para empresas devidamente licenciadas por órgãos ambientais e autorizadas pela ANVISA para a realização de procedimento de descarte.

A Raia Drogasil S.A. indica que atua de maneira responsável em relação aos resíduos que gera e ao impacto destes no meio ambiente, praticando a coleta seletiva e a logística reversa de produtos em lojas e Centros de Distribuição. A empresa divulga o Relatório de Sustentabilidade, adotando a metodologia da Global Reporting Initiative (GRI).

A companhia divulga dados referentes à coleta dos medicamentos para o descarte correto. Há 539 pontos de recolhimento de medicamentos vencidos, para a população de 15 estados, como uma forma para destiná-los de maneira adequada, evitando a contaminação de solos e lençóis freáticos. O volume de medicamentos/embalagens recolhidos em 2016, 2017 e 2018, foi de: 29,5 toneladas; 33,7 toneladas e 40 toneladas, respectivamente (RAIA DROGRASIL, 2019).

A empresa apresenta sua agenda de sustentabilidade, sendo um dos eixos: cuidar da saúde do planeta, no qual consta como diretriz a redução de resíduos gerados pelo negócio e viabilizar sua destinação adequada. Além de demonstrar a sua preocupação com os resíduos perigosos que são gerados em suas lojas, tais como: agulhas e seringas que normalmente são utilizadas na aplicação de injeções.

A Drogasil publicou as suas políticas socioambientais, destacando as práticas ambientais, entre elas a destinação adequada dos resíduos sólidos, incluindo os medicamentos descartados pelos clientes nas lojas. 
No Relatório de Sustentabilidade a empresa fornece informações sobre o desempenho quanto ao volume de resíduos provenientes do centro de distribuição destinados para reciclagem, apresentados na Tabela 3.

Tabela 3: Evidenciação dos resíduos reciclados (toneladas mil)
\begin{tabular}{l|c|c|c} 
RESí́DUOS & $\mathbf{2 0 1 6}$ & $\mathbf{2 0 1 7}$ & $\mathbf{2 0 1 8}$ \\
\hline Papelão & $2.591,1$ & $3.201,2$ & $3.456,3$ \\
\hline Plástico & 41,2 & 103,9 & 130,5 \\
\hline Madeira & 3,6 & 12,9 & 5,4 \\
\hline Sucata de Ferro & 2,2 & 2,2 & 4,8 \\
\hline Total & $\mathbf{2 . 6 3 8 , 1 0}$ & $\mathbf{3 . 3 2 0 , 2}$ & $\mathbf{3 . 5 9 7 , 7}$ \\
\hline
\end{tabular}

Fonte: Adaptado de Raia Drogasil, (2019).

\section{Discussão dos resultados}

A análise de conteúdo das demonstrações financeiras e notas explicativas evidenciou que as empresas pesquisadas não divulgaram nenhuma informação sobre os impactos ambientais relacionados aos resíduos sólidos nestes documentos.

O único documento que possibilita verificar os impactos ambientais referentes aos resíduos sólidos é o Relatório de Sustentabilidade, revelando-se o principal documento para análise dos impactos ambientais. Entretanto, a divulgação deste relatório não é obrigatória, tendo sido publicada por somente duas empresas ( $25 \%$ da amostra pesquisada), as quais utilizaram o modelo GRI para formulação.

No Relatório de Sustentabilidade é possível verificar o volume (em toneladas) de resíduos reciclados, volume (em toneladas) de medicamentos recolhidos e/ou a destinação desses resíduos, conforme demonstrado nas Tabelas 2 e 3.

Embora as empresas divulguem algumas informações ambientais no Formulário de Referência da CVM e no Relatório de Administração, essas informações limitam-se aos fatores de risco de questões socioambientais, especialmente em relação às exigências legais.

Constatou-se que as companhias divulgam, predominantemente, informações de natureza qualitativa e que há uma tendência de divulgar apenas as ações que elas tenham desenvolvido em prol do meio ambiente (projetos, campanhas e programas). Resultado que corrobora os achados de estudos relacionados (DO PATROCÍNIO et al., 2018; MONTEIRO; FERREIRA, 2007), nos quais percebeu-se que as empresas evidenciam mais critérios positivos, não existindo quase nenhuma menção relacionada aos critérios negativos, tais como acidentes, descumprimento da legislação ambiental e multas. 


\section{Considerações finais}

A evolução do pensamento em torno das questões ambientais tem ganhado mais espaço na sociedade, influenciando as políticas públicas e as empresas a desenvolverem atividades mais sustentáveis. Nesse sentido, a evidenciação de informações ambientais possibilita que as empresas desenvolvam seu papel social, ampliem a transparência e a percepção do seu valor de mercado.

A expectativa dos stakeholders é que a gestão das empresas esteja alinhada ao conceito de desenvolvimento sustentável e voltada para a geração do menor impacto ambiental possível, aplicando de forma adequada os recursos naturais disponíveis.

Considerando que os resíduos sólidos gerados pelas empresas que prestam serviços na área da saúde têm potencial de risco significativo para o meio ambiente e para a saúde pública, esta pesquisa buscou analisar a evidenciação dos impactos ambientais referentes aos resíduos sólidos, nas oito empresas do ramo de medicamentos com ações negociadas na B3. Para avaliar a evidenciação desses impactos, a análise de conteúdo dos documentos disponibilizados pelas empresas foi realizada, a fim de identificar se houve a divulgação do volume e a classificação dos resíduos sólidos produzidos; a destinação e tratamento dos resíduos sólidos; e a gestão adotada no gerenciamento dos resíduos (logística reversa, coleta, reutilização e reciclagem).

Entre os documentos analisados, o Relatório de Sustentabilidade foi o único documento que evidenciou os impactos ambientais referentes aos resíduos sólidos. No entanto, a adoção pela divulgação voluntária desse relatório foi baixa, pois apenas duas das oito empresas analisadas divulgaram o seu Relatório de Sustentabilidade.

Quanto às demais empresas, as informações ambientais disponíveis nos documentos analisados foram insuficientes e/ou inexistentes para que seja possível avaliar os impactos ambientais relacionados à gestão dos resíduos sólidos. De forma sintética, somente $25 \%$ da amostra evidenciou informações ambientais, referente ao volume (em toneladas) de resíduos reciclados, medicamentos recolhidos e destinação dos resíduos.

Não há um padrão predominante para divulgação de dados socioambientais, pois algumas empresas entendem que não geram impactos ambientais relevantes. A falta de exigência legal, a cultura empresarial e o não reconhecimento da sua responsabilidade social podem ser alguns fatores que explicam a ausência de informações a respeito dos resíduos sólidos gerados. Nesse sentido, uma das principais contribuições desta pesquisa é identificar a fraca evidenciação dos impactos ambientais relacionados aos resíduos sólidos pelas empresas do ramo de medicamentos no Brasil, enaltecendo a importância de conscientização e sensibilização sobre esse fato, tanto no meio acadêmico, quanto empresarial. 
No meio acadêmico pesquisas que relacionem as práticas sustentáveis das empresas de capital aberto ao valor de mercado e/ou ao desempenho organizacional podem evidenciar o quanto o papel socioambiental e a responsabilidade corporativa das empresas são considerados pelo mercado e o quanto se refletem no valor das suas ações.

No meio empresarial, nota-se que as companhias ainda precisam superar algumas barreiras internas (valores empresariais, custos, disponibilidade de recursos) e barreiras externas (sociedade, tecnologia, regulamentação governamental) para que haja maior evidenciação de dados ambientais. No entanto, a demanda por atividades mais sustentáveis e por transparência no gerenciamento de recursos, tende a colaborar para que as empresas assumam a responsabilidade pelos recursos utilizados e divulguem informações ambientais mais consistentes.

\section{Referências}

ANVISA - Agência Nacional de Vigilância Sanitária. Anuário estatístico do Mercado Farmacêutico 2018. Brasília, 2019. Disponível em: $<$ http://portal.anvisa.gov.br/documents/374947/3413536/Anu\%C3\%A1 rio+Estat $\%$ C3\%ADstico+do+Mercado+Farmac\%C3\%AAutico+-+2018/c24aacbf-4d0c46a7-bb86-b92c170c83e1>. Acesso em: 06 set. 2019.

ANVISA - Agência Nacional de Vigilância Sanitária. Resolução RDC no 222, de 28 de março de 2018. Regulamenta as boas práticas de gerenciamento dos resíduos de serviços de saúde e dá outras providências. Disponível em: $<$ http://portal.anvisa.gov.br/documents/10181/3427425/RDC 2222018 .pdf/c5 d3081d-b331-4626-8448-c9aa426ec410>. Acesso em: 06 set. 2019

BALBINO, M. L. C.; BALBINO, E. C. O descarte de medicamentos no Brasil: Um olhar socioeconômico e ambiental do lixo farmacêutico. Revista Brasileira de Estudos Jurídicos - Faculdades Santo Agostinho, v. 7, n. 1, p. 87-100, 2012. BRASIL. Ministério da Saúde. Agência Nacional de Vigilância Sanitária. Manual de gerenciamento de resíduos de serviços de saúde. Brasília: Ministério da Saúde, 2006.

BRASIL. Ministério do Meio Ambiente. Política Nacional de Resíduos Sólidos. Portal, 2019. Disponível em: <http://www.mma.gov.br/pol\%C3\%ADtica-deres\%C3\%ADduos-s\%C3\%B3lidos>. Acesso em: 14 jul. 2019.

BRASIL. Lei n. 12.305, de 2 de agosto de 2010. Institui a Política Nacional de Resíduos Sólidos; altera a Lei no 9.605, de 12 de fevereiro de 1998; e dá outras providências. Brasília, DF, Diário Oficial [da] República Federativa do Brasil, 3 de ago. de 2010.

B3 - Brasil, Bolsa, Balcão. Consulte as demonstrações financeiras, fatos relevantes, comunicados, entre outras informações importantes das empresas listadas na B3. 2019. Disponível em: $<$ http://bvmf.bmfbovespa.com.br/cias-listadas/empresaslistadas/BuscaEmpresaListada.aspx?segmento=Medicamentos+e+Outros+Pro dutos\&idioma=pt-br>. Acesso em: 20 nov. 2019. 
B3 - Brasil, Bolsa, Balcão. Índice de sustentabilidade empresarial (ISE). 2019. Disponível em: <http://www.b3.com.br/pt br/market-data-eindices/indices/indices-de-sustentabilidade/indice-de-sustentabilidadeempresarial-ise.htm>. Acesso em: 20 ago. 2019.

COSTA, D. A. O. Diagnóstico do sistema de coleta de resíduos de medicamentos pós-uso na cidade de Natal/RN. Monografia (Graduação em Engenharia Ambiental) - Universidade Federal do Rio Grande do Norte, Natal, 2019.

CMMAD - Comissão Mundial sobre Meio Ambiente e Desenvolvimento. Nosso futuro comum. 2a ed. Tradução de Our common future. 1a ed. 1988. Rio de Janeiro: Editora da Fundação Getúlio Vargas, 1991.

CVM - Comissão de Valores Mobiliários. Consulta de documentos de Companhias Abertas. 2019. Disponível em: $<$ https://cvmweb.cvm.gov.br/SWB/Sistemas/SCW/CPublica/CiaAb/FormBuscaC iaAb.aspx?TipoConsult=C>. Acessado em: 20 de nov. de 2019.

DE OLIVEIRA, O. V.; FERREIRA, V. H. F. A. Motivos da não evidenciação de relatórios socioambientais das companhias listadas no Novo Mercado da B3. Environmental \& Social Management Journal/Revista de Gestão Social e Ambiental, v. 12, n. 3, 2018.

DO PATROCíNIO, M. A. F.; MOURA, A. M.; SILVA, A. R. Nível de evidenciação ambiental das Companhias Siderúrgicas listadas na B3. Revista de Informação Contábil, [S.I.], v. 12, n. 1, p. 18-35, 2018.

GERHARDT, T. E.; SILVEIRA, D. T. Métodos de pesquisa. Plageder, 2009.

GIACOMIN, J. E.; Ott, E.; GRANDO, T. Estudo sobre variáveis determinantes do nível de divulgação de informação voluntárias ambientais. Revista de Gestão Ambiental e Sustentabilidade, São Paulo, Vol. 7, n. 1 p. 97-115, 2018.

KARLINER, J.; GUENTHER, R. Agenda Global Hospitais Verdes e Saudáveis: uma agenda abrangente de saúde ambiental para hospitais e sistemas de saúde em todo o mundo. 2011. Disponível em: $<$ http://www.hospitaissaudaveis.org/arquivos/GGHHA-Portugese.pdf $>$. Acesso em: 19 out. 2019.

MIKHAILOVA, I. Sustentabilidade: evolução dos conceitos teóricos e os problemas da mensuração prática. Revista Economia e Desenvolvimento, $\mathrm{n}^{\circ}$ 16, 2004.

MONTEIRO, P. R. A.; FERREIRA, A. C. S. A evidenciação da informação ambiental nos relatórios contábeis: um estudo comparativo com o modelo do ISAR/UNCTAD. Revista de Gestão Social e Ambiental, v. 1, n. 1, p. 82-101, 2007.

OLIVEIRA, Vera Eunice. Avaliação do Gerenciamento dos Resíduos Sólidos de um Hospital no Município de Minas Gerais. Revista Brasileira de Educação Ambiental, v. 15, $\mathrm{n}^{\circ} .7$, p. 59-70, 2020. 
OUROFINO. Relatório de Sustentabilidade 2018. Disponível em: $<$ https://ri.ourofino.com/show.aspx?idCanal=Qbsk/0MuuUlJr8HJhG1G+Q==>.

Acesso em: 20 nov. 2019.

PNUD - Programa das Nações Unidas para o Desenvolvimento. (2012). Estudos de casos de desenvolvimento sustentável na prática: "Ganhos triplos" para o desenvolvimento sustentável. 2012. Disponível em: $<$ https://www.undp.org/content/dam/undp/library/Cross-

Practice\%20generic\%20theme/ganhos triplos para desenvolvimento sustenta velissuu-portuguese.pdf>. Acesso em: 17 out. 2019.

RAIA DROGASIL S.A. Relatório Anual 2018. Disponível em: $<$ https://www.rd.com.br/show.aspx?idCanal=jS19Pe5uOxBlaJraxv+WCQ==>. Acesso em: 20 nov. 2019.

RICARDO, V. S.; BARCELLOS, S. S.; BORTOLON, P. M. Relatório de sustentabilidade ou relato integrado das empresas listadas na BM\&FBovespa: fatores determinantes de divulgação. Revista de Gestão Social e Ambiental, v. 11, n. 1, p. 90, 2017.

SILVA, T.; VICENTE, E.; PFITSCHER, E.; ROSA, F. Environmental disclosure informações sobre resíduos sólidos divulgadas pelas empresas potencialmente poluidoras listadas na BM\&FBOVESPA. Ambiente contábil, v. 5, n. 2, p. 229249, 2013.

SOUSA, A.C.A. A evolução da política ambiental no Brasil do século XX. Achegas.net, Rio de janeiro, v. I, n. 26, 2005.

SOUZA, C.D.F.A.; FALQUETO, E. Descarte de Medicamentos no Meio Ambiente no Brasil. Revista Brasileira Farmácia, v. 96, n. 2, p.1142-1158, 2015.

VOSS, B.; PFITSCHER, E. D.; ROSA, F.S.; RIBEIRO, M.S. Evidenciação Ambiental dos Resíduos Sólidos de Companhias Abertas no Brasil Potencialmente Poluidoras. Revista Contabilidade Financeira, São Paulo, v.24, n.62, p.12, 2013. 